УДК 502/504(075.8)

\title{
ИННОВАЦИОННЫЕ ПОДХОДЫ В ОБУЧЕНИИ ГЕОЭКОЛОГИИ
}

\author{
О. В. Крутова, Ю. А. Нестеров \\ Воронежский государственный университет, Россия \\ Поступила в редакиию 19 августа 2019 г.
}

\begin{abstract}
Аннотация: Отмечается перспективность применения геоинформационных технологий для теоретических и прикладных геоэкологических исследований, создания моделей оптимизации природопользования. В рамках курса «Геоэкология» проводятся практические занятия по дешифрированию данных дистанционного зондирования Земли, материалы которых ложатся в основу курсовой работы по геоэкологической оценке территории муниципальных образований Воронежской области с использованием технологий пространственного анализа средствами геоинформационных систем.

Ключевые слова: геоэкология, геоинформационные технологии, геоинформационные системы, дистанционное зондирование Земли, природопользование, Воронежская область.
\end{abstract}

\section{Innovative approaches in a teaching of geoecology O. V. Krutova, Yu. A. Nesterov}

\begin{abstract}
The prospects of the use of geoinformation technologies for theoretical and applied geoecological studies, the creation of models for optimizing nature management are noted. In the framework of the course «Geoecology», practical exercises are held to decipher the data of remote sensing of the Earth, the materials of which form the basis of the course work on geoecological assessment of the territory of municipalities of the Voronezh region using spatial analysis technologies using geographic information systems.

Key words: geoecology, geoinformation technologies, geoinformation systems, remote sensing of the Earth, nature management, Voronezh region.
\end{abstract}

Современное экологическое образование в высшей школе переживает этап определенного обновления и перестройки в связи с рядом проблем, которые обозначены в Концепции экологического образования в Российской Федерации, принятой на международной научно-практической конференции «Современная экология: образование, наука, практика», прошедшей в Воронежском госуниверситете в 2017 году, а также появлением и внедрением в учебный процесс нового федерального образовательного стандарта (3++) по направлению подготовки 05.03.06 «Экология и природопользование». В Концепции раскрывается суть современного этапа, связанного с радикальной модернизацией системы преподавания и обучения. Ключевой позицией в модернизации выступает «технологичность обучения», которую можно трактовать, с одной стороны, как максимальное сближение теоретических и прикладных аспектов в обучении,

(ㄷ) Крутова О.В., Нестеров Ю. А., 2019 a, с другой стороны, установление «вертикальных» межпредметных связей от младших курсов обучения к старшим. В последнем случае, необходимо поддерживать у студентов постоянный интерес к проблемным областям теоретических знаний в экологии и природопользовании. К ним можно отнести: соотношение экологии/геоэкологии и ландшафтоведения; представление об объекте и предмете исследования в геоэкологии; неопределенность понятия экосистема и ее пространственная безразмерность и некоторые другие. Знаменательна замена распространенного термина «геоэкология» «экологией», в чем усматривается определенный уход с географических позиций. Ниже рассмотрим некоторые представления об объекте и предмете геоэкологии как науки.

Первым ученым, употребившим слово «геоэкология», был немецкий географ К. Троль, а в России - написавший об этом в 1970 году В. Б. Сочава, который объяснил появление нового термина желанием К. Троля отразить экологическую на- 
правленность ландшафтоведения. Он подчеркивал, что типология лесов, пастбищных и других сельскохозяйственных угодий значительно выиграла, если бы строилась на ландшафтно-экологической основе. Таким образом, широко используемый ныне термин изначально был чисто географическим $[1,3]$.

По мнению Ф.Н. Милькова в связи с разнообразием и сложностью геоэкологических проблем при их решении необходима интеграция усилий различных наук. В качестве предмета исследования геоэкологии Ф.Н. Мильков предполагает изучение комфортности географической среды и оптимизацию ландшафта. [4]. Не случайно, определяя предмет геоэкологических/экологических исследований, Ф.Н. Мильков не останавливается на объекте этой отрасли естественных наук из-за его «размытости». Подобной точки зрения придерживается и В.Н. Двуреченский. Он в качестве общего предмета исследования геоэкологии, приемлемого для широкого ряда наук, склонен рассматривать направленные тенденции эволюционного и антропогенного изменения наиболее экологически значимых экопараметров геосферы как системы взаимосвязанных, континуально - дискретных саморазвивающихся зональных и региональных экосфер, образующих целостное единство с долговременно устойчивыми, эволюционно сформированными экопараметрами, принимаемыми за эталонные [2, 3].

«Геоэкологический подход реализуется на основе культурно-экологического, экогуманистического, ландшафтно-средового и пространственновременного подходов. Все они в совокупности создают целостную систему мировоззренческих установок на устойчивое развитие человечества на различных территориальных уровнях в единстве с природными основами жизни и составляют конкретно-научную методологическую основу развития геоэкологического образования» [9].

В связи с таким дискуссионным определением геоэкологии как науки ее преподавание, естественно, представляет определенные трудности и требует коренной перестройки. На факультете географии, геоэкологии и туризма Воронежского государственного университета в течение длительного времени осуществляются принципы сквозной подготовки студентов по направлению 05.03.06 «Экология и природопользование». С помощью этого принципа, не только достигаются межпредметные связи в преподавании, но и формируются основы «технологичности обучения». Так, в учеб- ных планах в шестом семестре значится дисциплина «Геоэкология». В соответствие с рабочей программой дисциплины планируемые результаты обучения заключаются в овладении базовыми физическими, химическими и биологическими знаниями в объеме, необходимом для освоения экологии и природопользования; методами химического анализа, знаниями о современных динамических процессах в природе и техносфере, о состоянии геосфер Земли, экологии и эволюции биосферы, глобальных экологических проблемах, методами отбора и анализа геологических и биологических проб, а также навыками идентификации и описания биологического разнообразия, его оценки современными методами количественной обработки информации. Объем дисциплины в зачетных единицах/час - 4/144. Форма промежуточной аттестации предполагает выполнение курсовой работы.

Курсовая работа по дисциплине «Геоэкология» предполагает следующую направленность: 1) написание в форме реферата (научного обзора по выбранной проблеме); 2) иметь практический, опытно-экспериментальный и технологический характер. В таком случае открывается возможность устанавливать межпредметные связи с дисциплиной «Геоинформационные системы в экологии и природопользовании», изучаемой в четвертом семестре этого же направления подготовки. Компетенции «Геоинформационных систем» и курса «Геоэкологии» совпадают.

Объем дисциплины «Геоинформационные системы» в зачетных единицах и часах составляет $2 / 72$, что достаточно для общего знакомства с геоинформационными системами, но слишком мало для приобретения устойчивых навыков работы в них. Для студентов необходимо предусмотреть перечень мотивов для систематического использования геоинформационных систем в области их будущей профессиональной деятельности. Как мы считаем, этого можно достичь через межпредметную связь дисциплин «Геоинформационные системы в экологии и природопользовании» и «Геоэкология».

В качестве примера реализации межпредметных связей обоих дисциплин можно привести материалы курсовых работ по «Геоэкологии», выполненных под руководством О.В. Крутовой (Прохоровой), несколькими поколениями бакалавров по направлению подготовки 05.03.06 «Экология и природопользование». Отметим некоторых студентов, успешно справившихся с заданием: 2014 год Акулова Е., Нгуен Ч. Х., Бухвалова Н., Якунин А., 
Таблица

Предварительные итоги расчета площадей типов землепользования по муниципальным образованиям Воронежской области

\begin{tabular}{|c|c|c|c|c|c|c|c|c|c|c|c|c|c|}
\hline \multirow{2}{*}{ Название района } & \multirow[t]{2}{*}{$\mathrm{S}, \mathrm{\kappa м}^{2}$} & \multicolumn{2}{|c|}{ Пашня } & \multicolumn{2}{|c|}{ Лeca } & \multicolumn{2}{|c|}{\begin{tabular}{|c|} 
Населенные \\
пункты
\end{tabular}} & \multicolumn{2}{|c|}{ Дороги } & \multicolumn{2}{|c|}{$\begin{array}{l}\text { Водные } \\
\text { объекты }\end{array}$} & \multicolumn{2}{|c|}{ БМЧЗ } \\
\hline & & км $^{2}$ & $\%$ & $\mathrm{KM}^{2}$ & $\%$ & $\kappa^{2}{ }^{2}$ & $\%$ & $\mathrm{KM}^{2}$ & $\%$ & $\mathrm{KM}^{2}$ & $\%$ & $\mathrm{KM}^{2}$ & $\%$ \\
\hline Аннинский & 2095 & 1208 & 57,6 & 155 & 7,4 & 94 & 4,5 & 5,5 & 0,26 & 39 & 1,84 & 594 & 28 \\
\hline Бобровский & 2231 & 1069 & 47,9 & 485 & 21,8 & 86 & 3,9 & 6,6 & 0,30 & 26 & 1,16 & 557 & 25 \\
\hline Богучарский & 2179 & 1157 & 53,1 & 146 & 6,7 & 43 & 2,0 & 8,8 & 0,40 & 19 & 0,88 & 806 & 37 \\
\hline Борисоглебский & 1368 & 709 & 51,8 & 265 & 19,4 & 93 & 6,8 & 4,8 & 0,35 & 30 & 2,22 & 267 & 20 \\
\hline Бутурлиновский & 1804 & 1025 & 56,8 & 194 & 10,7 & 27 & 1,5 & 3,3 & 0,18 & 12 & 0,67 & 543 & 30 \\
\hline Верхнемамонский & 1346 & 699 & 51,9 & 187 & 13,9 & 58 & 4,3 & 3,6 & 0,27 & 16 & 1,19 & 382 & 28 \\
\hline Верхнехавский & 1290 & 698 & 54,1 & 208 & 16,1 & 139 & 10,8 & 3,0 & 0,23 & 22 & 1,74 & 220 & 17 \\
\hline Воробьевский & 1236 & 762 & 61,6 & 56 & 4,5 & 71 & 5,8 & 2,8 & 0,22 & 6 & 0,52 & 338 & 27 \\
\hline Грибановский & 2013 & 995 & 49,4 & 426 & 21,2 & 108 & 5,4 & 4,4 & 0,22 & 19 & 0,93 & 461 & 23 \\
\hline Калачеевский & 2095 & 1187 & 56,7 & 120 & 5,7 & 105 & 5,0 & 6,4 & 0,30 & 4 & 0,20 & 671 & 32 \\
\hline Каменский & 998 & 507 & 50,8 & 35 & 3,5 & 44 & 4,5 & 2,4 & 0,25 & 2 & 0,23 & 406 & 41 \\
\hline Кантемировский & 2349 & 1385 & 59,0 & 72 & 3,1 & 149 & 6,3 & 6,8 & 0,29 & 10 & 0,41 & 726 & 31 \\
\hline Каширский & 1058 & 677 & 64,0 & 39 & 3,7 & 98 & 9,3 & 2,8 & 0,27 & 16 & 1,51 & 225 & 21 \\
\hline Лискинский & 1989 & 811 & 40,8 & 228 & 11,5 & 85 & 4,3 & 8,5 & 0,42 & 24 & 1,19 & 833 & 42 \\
\hline Нижнедевицкий & 1205 & 742 & 61,6 & 55 & 4,6 & 58 & 4,8 & 5,1 & 0,42 & 3 & 0,27 & 341 & 28 \\
\hline Новоусманский & 1233 & 710 & 57,6 & 142 & 11,5 & 253 & 20,5 & 4,0 & 0,33 & 14 & 1,12 & 111 & 9 \\
\hline Новохоперский & 2348 & 1220 & 52,0 & 279 & 11,9 & 63 & 2,7 & 7,5 & 0,32 & 54 & 2,29 & 725 & 31 \\
\hline Ольховатский & 1042 & 480 & 46,1 & 76 & 7,3 & 55 & 5,3 & 3,9 & 0,38 & 2 & 0,24 & 424 & 41 \\
\hline Острогожский & 1725 & 669 & 38,8 & 218 & 12,6 & 112 & 6,5 & 5,4 & 0,31 & 21 & 1,22 & 700 & 41 \\
\hline Павловский & 1870 & 963 & 51,5 & 306 & 16,3 & 91 & 4,8 & 3,5 & 0,19 & 21 & 1,13 & 486 & 26 \\
\hline Панинский & 1400 & 936 & 66,9 & 35 & 2,5 & 29 & 2,1 & 4,7 & 0,33 & 36 & 2,60 & 359 & 26 \\
\hline Петропавловский & 1642 & 940 & 57,3 & 181 & 11,0 & 80 & 4,8 & 3,3 & 0,20 & 7 & 0,45 & 431 & 26 \\
\hline Поворинский & 1079 & 615 & 57,0 & 151 & 14,0 & 59 & 5,5 & 2,9 & 0,27 & 24 & 2,21 & 227 & 21 \\
\hline Подгоренский & 1589 & 745 & 46,9 & 169 & 10,6 & 64 & 4,0 & 4,4 & 0,28 & 12 & 0,78 & 594 & 37 \\
\hline Рамонский & 1269 & 600 & 47,3 & 275 & 21,6 & 136 & 10,7 & 5,5 & 0,43 & 13 & 1,01 & 240 & 19 \\
\hline Репьевский & 929 & 506 & 54,4 & 55 & 5,9 & 50 & 5,4 & 3,8 & 0,40 & 3 & 0,34 & 311 & 33 \\
\hline Россошанский & 2373 & 1297 & 54,6 & 146 & 6,2 & 212 & 9,0 & 9,1 & 0,38 & 8 & 0,33 & 700 & 30 \\
\hline Семилукский & 1583 & 943 & 59,5 & 104 & 6,5 & 201 & 12,7 & 9,7 & 0,61 & 13 & 0,81 & 314 & 20 \\
\hline Таловский & 1910 & 1133 & 59,3 & 65 & 3,4 & 118 & 6,2 & 9,6 & 0,50 & 33 & 1,71 & 551 & 29 \\
\hline Терновский & 1389 & 839 & 60,4 & 95 & 6,9 & 102 & 7,4 & 2,7 & 0,19 & 9 & 0,66 & 341 & 25 \\
\hline Хохольский & 1452 & 693 & 47,7 & 174 & 12,0 & 81 & 5,6 & 2,9 & 0,20 & 23 & 1,57 & 479 & 33 \\
\hline Эртильский & 1468 & 903 & 61,5 & 31 & 2,1 & 103 & 7,0 & 3,6 & 0,24 & 18 & 1,19 & 410 & 28 \\
\hline
\end{tabular}

Субботин А.; 2015 - Гусаков Д., Никулин В.; 2016 - Быкова Д., Нагих Т.; 2017 - Багмутова Т., Горлова В., Прохоров А., Кондратьева О., Ефремов А.

Предложенная тематика курсовых работ была нацелена на применение геоинформационных технологий (ПО MapInfo или QGIS) и данных дистанционного зондирования Земли (ДДЗ) при оценке структуры землепользования муниципальных образований [6]. 
Базовым слоем служит Google Satellite из сети Интернет, который доступен через плагин OpenLayers в среде QGIS. В результате визуального ручного дешифрирования космических снимков высокого разрешения студентами создаются векторные слои: пашня, лесополосы, леса, водные объекты, населенные пункты, дороги, сады и другие.

Обобщенные нами данные студенческих работ: общая площадь района и площади основных типов использования территории (абсолютные значения выражены в км², относительные - в \% к площади соответствующего района), представлены в таблице. Безлесными малоиспользуемыми человеком землями (БМЧЗ) в таблице названы оставшиеся после ручной оцифровки «белые пятна» - это пастбища, сенокосы, залежи, крутые склоны с обнажениями горных пород и другое.

Не ставя целью подробный анализ результатов исследования ввиду их возможных погрешностей (например, в результате случайного копирования полигонов или намеренного игнорирования мелких объектов), хочется отметить, что они вполне согласуются с официальными данными и здравым смыслом.

Так, наибольшая относительная распаханность территории отмечена для Панинского района $(66,9 \%)$, который в геоморфологическом плане относится к Окско-Донской равнине и имеет четко выраженную сельскохозяйственную специализацию. Самые лесопокрытые районы - Бобровский, Рамонский и Грибановский (Хреновской бор, Воронежский заповедник, Теллермановская роща)

Очевидно, что ввиду близости к областному центру наибольшей антропогенной трансформации подвергается территория Новоусманского района. Относительная площадь населенных пунктов здесь составляет 20,5 \% (максимальный показатель в области). Численность населения Новоусманского района постоянно увеличивается, что активизирует строительство новых жилых кварталов. В районе развито сельское хозяйство, распахано 57,6\% территории. Согласно нашим исследованиям площадь неиспользуемых территорий составляет всего $9 \%$.

Таким образом, по предварительным данным 11 районов Воронежской области имеют более $30 \%$ БМЧЗ: Лискинский, Каменский, Ольховатский, Богучарский, Кантемировский. Это наиболее перспективные районы для расширения сети особо охраняемых природных территорий, в особенности, степных, а также для развития экологического туризма. В 16 районах БМЧЗ составляет от
20 до $30 \%$. И лишь в 5 районах БМЧЗ имеют менее $20 \%$ : Семилукский, Борисоглебский, Рамонский, Верхнехавский, Новоусманский [7]. Благоприятные ландшафтно-экологические условия, близость к областному центру, высокая плотность населения предопределили высокую степень антропогенной трансформации ландшафтов этих районов.

Полученные результаты дешифрирования и последующего геоинформационного картографирования типов использования земель (природных комплексов) подчеркивают необходимость их проверки в полевых условиях на эталонных участках, которое было осуществлено, в частности, на территории природного архитектурно-археологического музея-заповедника «Дивногорье» [8]. В нашей методике результат считается удовлетворительным при $75 \%$ совпадении с эталонами [7].

В последующем межпредметная связь рассмотренных дисциплин продолжается и реализуется в курсе «Цифровые модели геополей». До введения на факультете двухуровневого обучения в 2011 году цифровое моделирование геополей рассматривалось только в разделе тематического картографирования средствами ГИС-пакетов, что исключало возможность детального знакомства с возможностями анализа реальных и абстрактных геополей, и смежных экологических дисциплин.

В 2012 году на кафедре геоэкологии и мониторинга окружающей среды разработана рабочая программа «Цифровые модели геополей» (ЦМГ), которая реализуется в учебном процессе с 20142015 учебного года.

Программа предусматривает изложение теоретических основ создания ЦМГ как реальных географических и геоэкологических объектов и явлений, так и абстрактных геополей.

Основные задачи дисциплины состоят в том, что студенты изучают процесс создания ЦМГ, используя различные методы от оцифровки сканированных или иных растровых изображений до трехмерных моделей.

Дисциплина ЦМГ относится к вариативной части учебного плана. Ее освоение студентами предполагает владение математическим аппаратом статистической обработки данных, основами компьютерной графики, знанием географических информационных систем, картографии, топографии, геоэкологического картографирования. Студенты приобретают навык работы с программными комплексами, используемыми в работе по созданию ЦМГ; строят цифровые модели, умеют их анали- 
зировать и дают квалифицированную географическую и геоэкологическую интерпретацию полученным данным.

При изучении дисциплины особое внимание уделяется географически грамотной интерпретации данных ЦМГ и представлению об относительной ограниченности применения ЦМГ для решения научных, прикладных задач, а также для составления рекомендаций и прогнозов развития явлений. При проведении практических занятий соблюдается принцип исторической динамики развития науки, технологий и теории познания мира от созерцательного: «внешние природные признаки», до математического - создание моделей прогнозов развития явлений [5]. Дидактическим материалом в завершающем курсе «Цифровые модели геополей» служат имеющиеся у студентов данные из курсовой работы по дисциплине «Геоэкология».

\section{СПИСОК ЛИТЕРАТУРЫ}

1. Горшков С. П. Концептуальные основы геоэкологии / С. П. Горшков. - Смоленск : Издательство Смоленского государственного университета, 1998. - 447 с.

2. Двуреченский В. Н. Проблемы геоэкологии / В. Н. Двуреченский. - Воронеж : Издательство Воронежского государственного университета, 2003. - 32 с.

3. Крутова О. В. Геоэкология / О. В. Крутова. - Воронеж : Издательский дом Воронежского государственного университета, 2019. - 64 с.

4. Мильков Ф. Н. Геоэкология как междисциплинарная наука о комфортности географической среды и оптимизации ландшафта / Ф. Н. Мильков // Известия Русского географического общества. - 1997. - Вып. 3. - C. 54-59.

5. Нестеров Ю. А. «Цифровые модели геополей» в подготовке бакалавров и магистров по направлениям «Экология и природопользование» и «География» // Ю. А. Нестеров // Информатика: проблемы, методология, технологии. - 2013. - Т. 4. - С. 321-325.

6. Прохорова О. В. Методические указания для выполнения заданий производственной практики по расширению сети особо охраняемых природных территорий с применением геоинформационных технологий и данных дистанционного зондирования Земли / О. В. Прохорова. - Воронеж : Цифровая полиграфия, 2012. $-36 \mathrm{c}$.

7. Прохорова О. В. Опыт применения ГИС-технологий при написании курсовых работ по «Геоэкологии» / О. В. Прохорова, В. А. Никулин, А. Д. Прохоров // Геоинформационное картографирование в регионах России. - Воронеж : Научная книга, 2016. - С. 105-109.
8. Распространение редких и охраняемых видов растений на территории природного архитектурно-археологического музея-заповедника «Дивногорье» / В. А. Агафонов [и др.] // Вестник Воронежского государственного университета. Сер. География. Геоэкология. - 2019. - № 2. - С. 86-90.

9. Шевченко И. А. Инновационные подходы геоэкологического образования как методологическая основа формирования культуры природопользования / И. А. Шевченко, Е. В. Кутасова // Современные наукоемкие технологии. - 2016. - № 2-1. - С. 180-183.

\section{REFERENCES}

1. Gorshkov S. P. Kontseptual'nye osnovy geoekologii / S. P. Gorshkov. - Smolensk : Izdatel'stvo Smolenskogo gosudarstvennogo universiteta, 1998. - $447 \mathrm{~s}$.

2. Dvurechenskiy V. N. Problemy geoekologii / V. N. Dvurechenskiy. - Voronezh : Izdatel'stvo Voronezhskogo gosudarstvennogo universiteta, 2003. $-32 \mathrm{~s}$.

3. Krutova O. V. Geoekologiya / O. V. Krutova. - Voronezh : Izdatel'skiy dom Voronezhskogo gosudarstvennogo universiteta, 2019. - $64 \mathrm{~s}$.

4. Mil'kov F. N. Geoekologiya kak mezhdistsiplinarnaya nauka o komfortnosti geograficheskoy sredy i optimizatsii landshafta / F. N. Mil'kov // Izvestiya Russkogo geograficheskogo obshchestva. - 1997. - Vyp. 3. - S. 54-59.

5. Nesterov Yu. A. «Tsifrovye modeli geopoley» v podgotovke bakalavrov i magistrov po napravleniyam «Ekologiya i prirodopol'zovanie» i «Geografiya»// Yu. A. Nesterov // Informatika: problemy, metodologiya, tekhnologii. - 2013. - T. 4. - S. 321-325.

6. Prokhorova O. V. Metodicheskie ukazaniya dlya vypolneniya zadaniy proizvodstvennoy praktiki po rasshireniyu seti osobo okhranyaemykh prirodnykh territoriy s primeneniem geoinformatsionnykh tekhnologiy i dannykh distantsionnogo zondirovaniya Zemli / O. V. Prokhorova. - Voronezh : Tsifrovaya poligrafiya, 2012. $-36 \mathrm{~s}$.

7. Prokhorova O. V. Opyt primeneniya GIS-tekhnologiy pri napisanii kursovykh rabot po «Geoekologii» / O. V. Prokhorova, V. A. Nikulin, A. D. Prokhorov // Geoinformatsionnoe kartografirovanie $\mathrm{v}$ regionakh Rossii. - Voronezh : Nauchnaya kniga, 2016. -S. 105-109.

8. Rasprostranenie redkikh i okhranyaemykh vidov rasteniy na territorii prirodnogo arkhitekturno-arkheologicheskogo muzeya-zapovednika «Divnogor'e»/V. A. Agafonov [i dr.] // Vestnik Voronezhskogo gosudarstvennogo universiteta. Ser. Geografiya. Geoekologiya. - 2019. - № 2. -S. 86-90.

9. Shevchenko I. A. Innovatsionnye podkhody geoekologicheskogo obrazovaniya kak metodologicheskaya osnova formirovaniya kul'tury prirodopol'zovaniya / I. A. Shevchenko, E. V. Kutasova // Sovremennye naukoemkie tekhnologii. - 2016. - № 2-1. - S. 180-183. 
Крутова Ольга Владимировна

кандидат географических наук, доцент кафедры рекреационной географии, страноведения и туризма факультета географии, геоэкологии и туризма Воронежского государственного университета, г. Воронеж, т. (473)266-56-54, E-mail: prokhorova.vsu@mail.ru

Нестеров Юрий Анатольевич

кандидат географических наук, доцент кафедры геоэкологии и мониторинга окружающей среды факультета географии, геоэкологии и туризма Воронежского государственного университета, г. Воронеж, т. (473) 266-56-54, E-mail: nland58@ mail.ru
Krutova Olga Vladimirovna

Candidate of Geographical Sciences, Associate professor of the Department of recreational geography, regional studies and tourism of the Geography, Geoecology and Tourism Faculty of the Voronezh State University, Voronezh, tel. (473)266-56-54, E-mail: prokhorova.vsu@ mail.ru

Nesterov Yuriy Anatolyevitch

Candidate of Geographical Sciences, Associate professor of the chair of geoecology and monitoring of environment of the department of geography, geoecology and tourism, Voronezh State University, Voronezh, tel. (473) 266-56-54, E-mail: nland58@ mail.ru 